\title{
Critical wind and turbidity rise in a shallow Florida lake
}

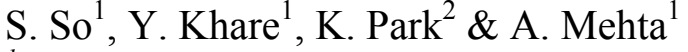 \\ ${ }^{1}$ College of Engineering, University of Florida, Gainesville, Florida, USA \\ ${ }^{2}$ St Johns River Water Management District, Palatka, Florida, USA
}

\begin{abstract}
At shallow lakes laden with organic muck the relationship between wind and bottom erosion flux which influences turbidity is a matter of interest to lake management. This relationship is assessed in reference to Lake Apopka in central Florida. Time-series of data on the suspended sediment concentration (SSC) and wind speed were obtained during a field experiment. The data have been used to describe the behavior of the critical wind speed for rise in SSC and the dependence of erosion flux on the bed shear stress in conjunction with six erosion equations. The critical wind speed appeared to be higher during cool water months compared to warmer conditions possibly because, in addition to likely biogenic effects, fine sediment erosion flux varies with water temperature. Although a more robust set of data is required for a fuller assessment of the applicability of the equations, it is tentatively inferred that two of the six equations that incorporate the notion of a maximum erosion flux cap may not be consistent with natural erosion behavior.
\end{abstract}

Keywords: eutrophication, sediment erosion, sediment resuspension, water quality, wind waves.

\section{Introduction}

The quality of water in lakes is a matter of much interest in the state of Florida (USA) with about 7,700 lakes greater than about 4 ha in area (State of Florida [1]). The bottom sediment in many lakes is organic muck that is easily resuspended by wind-induced waves and currents where the depth of water is less than about $3 \mathrm{~m}$. Nutrients sequestered in muck and released during wind events contribute to the production of extensive algal blooms and macrophytes. 
For several highly eutrophied lakes the state's water management agencies have developed plans for restoration, in which a key issue is related to the critical wind speed for turbidity generation due to suspended matter.

Rule of thumb values of the critical wind speed above which the suspended sediment concentration (SSC) rises rapidly are needed. Furthermore, for a description of turbidity dynamics the bed erosion flux is required as a function of the bottom shear stress when it exceeds the bed shear strength resisting erosion. These factors are examined with reference to Lake Apopka in central Florida. An extensive field experimental study was carried out in that lake during 2007-2008 using transducers to measure relevant physical parameters at three stations (So [2]). Time-series of flow and SSC data have been used to briefly describe the behavior of critical wind speed and examine the dependence of erosion flux on bed shear stress in conjunction with equations for erosion selected from the literature.

\section{Wind speed and erosion}

The critical wind speed $U_{c}$ is the threshold value of wind speed $U$ below which entrainment of sediment at the bed is low (Fig. 1). Thus an increase in SSC (Type A rise) may not measurably reduce the clarity of water measured by, for example, a Secchi disc. When $U$ exceeds $U_{c}$, SSC rises at a comparatively much higher rate (Type B rise). Under a steady wind, in the long run two factors may reduce the rate of rise of SSC (Type C rise). There can be depletion of the top bed layer of erodible sediment exposing the bed surface that is denser and more resistant to erosion. This is an armoring effect similar to one at a sandy bed where, after the smaller grains are winnowed out by erosion, the surface is covered with larger, less erodible grains. Fully effective armoring would mean no further increase in SSC (dashed horizontal line). Another effect is the damping of near-bed turbulence at high SSC resulting in a reduction in the capacity of flow to carry suspended particles.

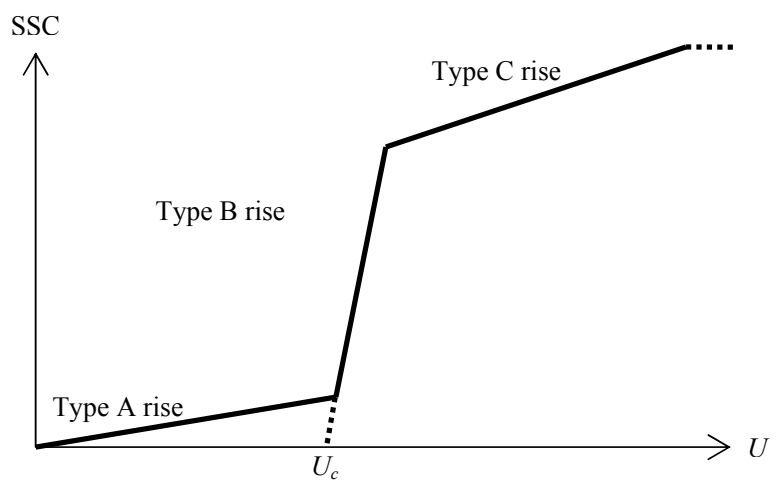

Figure 1: Definition of critical wind speed. 
The parameter $U_{c}$ is estimated by extrapolating the Type B curve approximated as a straight line (Fig. 1). However, the rate of SSC rise is more precisely governed by the bed shear stress $\tau_{b}$ than by wind speed. Thus $U_{c}$ is a rough indicator of the onset of significant erosion, even though it has importance as a rule-of-thumb variable in preliminary assessments of bed stability against rapid rise in turbidity. The bed shear stress varies with the wind velocity, the drag coefficient at the water surface, water depth, hydraulic bed roughness and properties of the bottom boundary layer. In other words the dependence of $\tau_{b}$ on wind speed $U$ is not unique. Furthermore, since wind induces waves and water current, $\tau_{b}$ is dependent on both. Thus the basic relationship underpinning the rise of boundary-layer SSC with wind speed is the dependence of the flux $\varepsilon$ (as dry sediment mass per unit bed area per unit time) of particles eroded from the bed on $\tau_{b}$. Six selective expressions of the form $\varepsilon\left(\tau_{b}\right)$ are given in Table 1 . They are inter-related as follows.

Equation (1) of Partheniades [3] considers the instantaneous bed shear stress $\tau_{b}(t)$ to be the sum of a time-mean value $\tau_{b}$ and a turbulent fluctuation $\tau_{b}(t)$ with a normal frequency distribution $\tau_{b}$ (where $t$ is time and $\omega$ is a dummy variable). The coefficient $k$, which has physical meaning within the stochastic framework, and $\varepsilon_{\max }$ are dependent on the sediment. The maximum value of the term within brackets, which can be shown to be the probability of erosion, is 1 . Therefore $\varepsilon_{\max }$ is the maximum erosion flux $\varepsilon$. At low bed shear stresses the predictive ability of eqn (1) is reasonable; however, at high $\tau_{b}$, since $\varepsilon$ cannot exceed $\varepsilon_{\max }$, erosion may be significantly under-predicted by this equation.

Equation (2) of Christensen [4] introduces a correction in eqn (1) by considering the flow velocity $u(t)$, the basic variable governing turbulence, to have a random frequency distribution. Therefore the distribution of $\tau_{b}$, which has a quadratic dependence on $u$ in turbulent flows, is non-normal. It was also suggested that $\varepsilon_{\max }$ may not be constant; however, this is not accounted for in eqn (2). The physical meaning of coefficient $k^{\prime}$ is derived from a stochastic framework similar but not identical to the basis of eqn (1).

Regarding $\varepsilon_{\max }$, van Prooijen and Winterwerp [5] pointed out that the characteristic time over which dissociation and transport of a bed particle or floc takes place cannot be constant as assumed in eqns (1) and (2), but must change as $\tau_{b}$ changes. As $\tau_{b}$ increases the characteristic time should decrease and vice versa. As a separate consideration, $\varepsilon$ must be related to $\tau_{b}$ in excess of the bedmean shear strength $\tau_{s}$ resisting erosion, i.e. on $\tau_{b}-\tau_{s}$. In the resulting expression, Eq. (3), $M$ is an empirical flux constant, $\tau_{s}^{*}=\alpha \hat{\tau}_{s}-\beta \delta^{2}, \hat{\tau}_{s}=\tau_{s} / \tau_{b}\left(1+\delta^{2}\right), \rho_{w}$ is the water density, $\sigma_{u}=\sqrt{\left(1+\delta^{2}\right) \bar{\tau}_{b} / \rho_{w}}$ is the standard deviation of a normally distributed characteristic near-bed velocity $u_{b}(t)$ with a mean value $u_{b}$, and $\delta=u_{b} / \sigma_{u}$. Best-fit values of the coefficients $\alpha$ and $\beta$ were based on a previously measured frequency distribution of $\tau_{b}$.

Equation (4) is a polynomial approximation of eqn (3) with sediment dependent coefficients $a_{1}$ through $a_{4}$. The severity of approximation makes eqn (4) entirely empirical without association with the stochastic basis of eqn (3). An advantage of eqn (4) is that in some cases it may be sufficient to consider just 
one term within brackets, which reduces the expression to a linear, quadratic or third-order polynomial, each with a single free coefficient.

In eqn (5) the stochastic basis of eqn (3) has been extended by treating the shear strength $\tau_{s}$ as the sum of the spatial mean value $\tau_{s}$ and a component $\tau_{s}$ varying over the bed surface. The quantities $\varphi\left(\tau_{b}\right)$ and $\varphi\left(\tau_{s}\right)$ are the frequency distributions of $\tau_{b}$ and $\tau_{s}$, respectively, and $C_{\varepsilon}$ is a characteristic erosion-related concentration. The distribution is $\varphi\left(\tau_{b}\right)$ produced from the corresponding random distribution of turbulent velocity $u$ and the dependence of $\tau_{b}$ on $u^{2}$ (quadratic law). Thus $\varphi\left(\tau_{b}\right)$ does not have a prescribed canonical form. The $\varphi\left(\tau_{s}\right)$ distribution is conveniently taken to be normal. The heavyside function $H(\theta)=0$ if $\theta<0,1$ if $\theta>0$ and 0.5 if $\theta=0$. Fuller development is found in Letter and Mehta [6].

Empirical eqn (6), which is the linear form of eqn (4) with erosion flux constant $M^{\prime}$, was originally proposed by Ariathurai [7].

Table 1: $\quad$ Selected erosion flux expressions.

\begin{tabular}{|c|c|c|}
\hline Erosion flux $\varepsilon$ & Source & Eqn \\
\hline$\varepsilon_{\max }\left\{1-\frac{1}{2}\left[\begin{array}{c}\operatorname{erf}(\omega)^{\frac{k}{\bar{\tau}_{b}}-2} \\
-\frac{k}{\bar{\tau}_{b}}-2\end{array}\right]\right.$ & $\begin{array}{l}\text { Partheniades } \\
\text { [3] }\end{array}$ & (1) \\
\hline$\varepsilon_{\max }\left\{\frac{1}{2}-\frac{1}{2}\left[\operatorname{erf}(\omega)_{0}^{\frac{k^{\prime}}{\sqrt{\bar{\tau}_{b}}}-6.1}\right]\right.$ & $\begin{array}{l}\text { Christensen } \\
{[4]}\end{array}$ & (2) \\
\hline$M \rho_{w} \sigma_{u}^{2}\left[\begin{array}{l}\frac{\delta^{2}-\tau_{s}^{*}+1}{2 \alpha}+\frac{\delta+\sqrt{\tau_{s}^{*}}}{\alpha \sqrt{2 \pi}} \exp \left(\delta \sqrt{\tau_{s}^{*}}-\frac{\tau_{s}^{*}}{2}-\frac{\delta^{2}}{2}\right) \\
+\frac{\delta^{2}-\tau_{s}^{*}+1}{2 \alpha} \operatorname{erf}\left(\frac{\delta}{\sqrt{2}}-\sqrt{\frac{\tau_{s}^{*}}{2}}\right)\end{array}\right]$ & $\begin{array}{l}\text { van Prooijen } \\
\text { and } \\
\text { Winterwerp } \\
{[5]}\end{array}$ & (3) \\
\hline$M \bar{\tau}_{s}\left[a_{1}\left(\frac{\bar{\tau}_{b}}{\bar{\tau}_{s}}\right)^{3}+a_{2}\left(\frac{\bar{\tau}_{b}}{\bar{\tau}_{s}}\right)^{2}+a_{3}\left(\frac{\bar{\tau}_{b}}{\bar{\tau}_{s}}\right)+a_{4}\left(\frac{\bar{\tau}_{b}}{\bar{\tau}_{s}}-1\right)\right]$ & $\begin{array}{l}\text { van Prooijen } \\
\text { and } \\
\text { Winterwerp } \\
{[5]}\end{array}$ & (4) \\
\hline 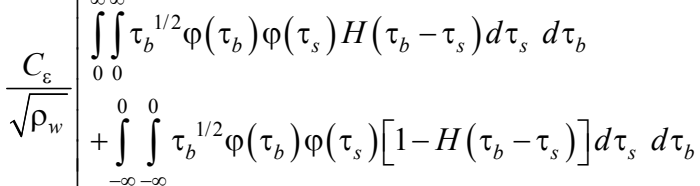 & $\begin{array}{l}\text { Letter and } \\
\text { Mehta [6] }\end{array}$ & (5) \\
\hline$M^{\prime}\left(\bar{\tau}_{b}-\bar{\tau}_{s}\right)$ & $\begin{array}{l}\text { Ariathurai } \\
{[7]}\end{array}$ & (6) \\
\hline
\end{tabular}




\section{Experiment}

\subsection{Field deployments}

Lake Apopka with a surface area of about 12,500 ha occurs about $25 \mathrm{~km}$ northwest of the Orlando metropolitan area in Florida (Fig. 2). Historically it has been one of the most contaminated lakes in the state. At the time of the experiment the maximum depth of water was about $2.7 \mathrm{~m}$ at the center of the lake, and the mean depth about $1.65 \mathrm{~m}$. Three freshwater sources along the eastern shoreline, one of which is Apopka Spring (shown), feed the lake. The Apopka-Beauclair Canal, which has a flow control structure, is the only outlet. Until 1946-47 the lake was clear with extensive submersed plant beds. Contamination is believed to have resulted from excessive phosphorus loading, mainly out of a large farming area developed on a floodplain marsh north of the lake (Lowe et al. [8]). On average the bottom muck has $62 \%$ organic matter by weight with a low mean particulate density of $1,690 \mathrm{~kg} \mathrm{~m}^{-3}$ (compared to the nominal $2,650 \mathrm{~kg} \mathrm{~m}^{-3}$ for the mineral component of muck). As a result organic aggregates are easily resuspended at low to moderate wind speeds.

Measurements relevant to erosion were carried out at three (Fig. 2) platforms with adequate water depths in the dry season and keeping in mind the dominance of (northeasterly) winds from $\mathrm{N}^{\circ} 0^{\circ} \mathrm{E}$ (So [2]). UF0 was the primary station at the site of the St. Johns River Water Management District meteorological tower. At this station an acoustic Doppler current profiler (ADCP), a wave sensor (SBE) and two optical backscatter sensors (OBS) were mounted. At each of stations UF1 and UF2 an ADCP and an OBS were installed. The OBS were carefully calibrated in the laboratory using suspended sediment collected near

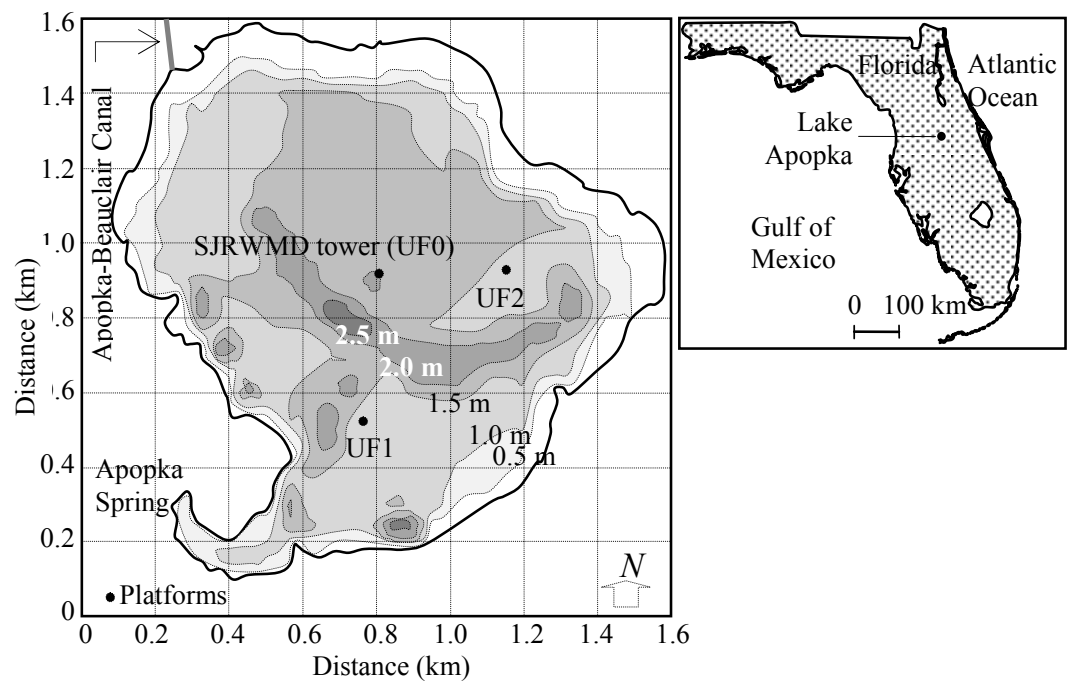

Figure 2: $\quad$ Lake Apopka in central Florida. 
UF0. Every two weeks all transducers were retrieved, downloaded, cleaned and reinstalled. Altogether nine successful deployments, each lasting several weeks, were made (Table 2). The first deployment was on July 25, 2007, and final decommissioning took place on September 16, 2008. Sampling was carried out every hour at specified frequencies (Table 3). Barring downtime, measurements were continuous; however, equipment malfunction and weather led to several discontinuities. For the present analysis, synchronous time-series of wind, water level, current and SSC were used.

At UF0, hourly wind speed $U$ was recorded by an anemometer $10 \mathrm{~m}$ above the water surface. Each value was a 3-minute average. The cumulative frequency distribution of $U$ in Fig. 3 is based on the period from 2002 to 2008. During the 2007-2008 study period, excluding downtime the wind speed ranged between nil and $22.8 \mathrm{~m} \mathrm{~s}^{-1}$ with a mean of $4.06 \mathrm{~m} \mathrm{~s}^{-1}$ (which was slightly higher than $3.89 \mathrm{~m} \mathrm{~s}^{-1}$ for the entire period).

Table 2: Deployments, periods and critical wind speeds.

\begin{tabular}{ccc}
\hline \hline Deployment & Period & $\begin{array}{c}U_{c} \\
\left(\mathrm{~m} \mathrm{~s}^{-1}\right)\end{array}$ \\
\hline UF0-01 & July-August 2007 & 4 \\
UF0-02 & August-September 2007 & 4 \\
UF0-03 & September-October 2007 & 4 \\
UF0-04 & October-December 2007 & 4.5 \\
UF0-05 & December 2007-January 2008 & 6 \\
UF0-06 & January-March 2008 & 6.5 \\
UF0-10 & August-September 2008 & 4 \\
UF1-01 & April-June 2008 & 4 \\
UF2-01 & August-September 2008 & 5 \\
\hline \hline
\end{tabular}

Table 3: $\quad$ Description of relevant transducers.

\begin{tabular}{cccc}
\hline \hline Parameter & Make & Model & $\begin{array}{c}\text { Sampling } \\
\text { frequency (Hz) }\end{array}$ \\
\hline $\begin{array}{c}\text { Current } \\
\text { velocity }\end{array}$ & RD Instruments & $\begin{array}{c}\text { Workhorse Sentinel } \\
\text { (ADCP) }\end{array}$ & $0.5,1$ \\
$\begin{array}{c}\text { Wave } \\
\text { height }\end{array}$ & Sea-Bird Electronics & SBE 26-03 & 4 \\
SSC & D \& A Instruments & OBS-3 & 1 \\
\hline \hline
\end{tabular}




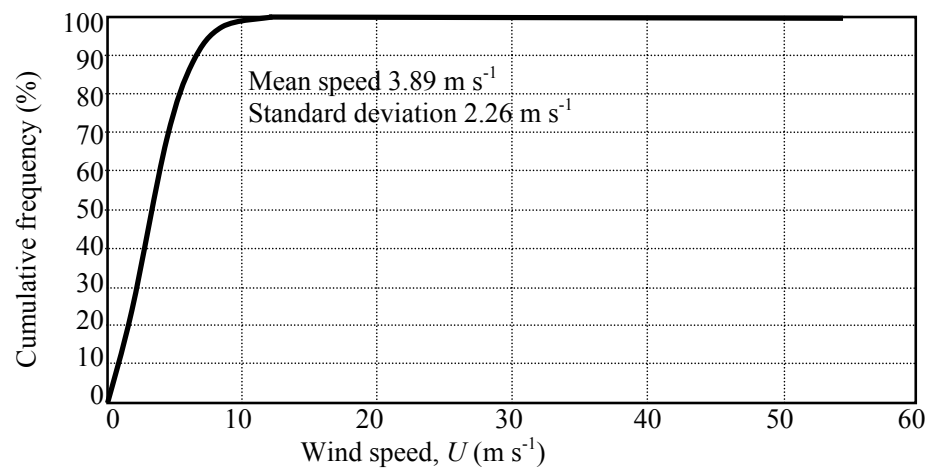

Figure 3: Cumulative frequency distribution on wind speed at UF0 for the period 2002-2008. The mean speed was $3.89 \mathrm{~m} \mathrm{~s}^{-1}$ and standard deviation $2.26 \mathrm{~m} \mathrm{~s}^{-1}$.

Water level data yielded the depth of water, wave height and period. Due to the unsteady wind field, temporal and spatial variability in hydrodynamics is high in the lake. Figure 4 is a typical plot of wind-driven depth-mean instantaneous flow circulation. The pattern was simulated by applying a threedimensional hydrodynamic numerical model, the Environmental Fluid Dynamics Code, which was calibrated against water level and current data from the lake (Mehta and Hayter [9]). The main (anti-cyclonic) gyre is seen to be at the scale of the lake, and smaller cells are configured by the main gyre and local shoreline geometry. Lateral shear zones are apparent at confluent flow boundaries.

\subsection{Estimation of bed shear stress}

In the remaining description, overbars indicating mean values of bed shear stress and bed shear strength are dropped for convenience. The time-series of bed shear stress $\tau_{b}$ was obtained from wind, water level and current and using

$$
\tau_{b}=\chi\left(\tau_{b w}+\tau_{b c}\right)
$$

where $\chi$, the wave shear stress $\tau_{b w}$ and the current shear stress $\tau_{b c}$ are evaluated from a series of formulas calibrated against data on wave height, wave period and water current. The essential method of calculation of $\tau_{b}$ from eqn (7) is given in Soulsby et al. [10].

The significant wave height $H_{s}$ and spectral peak wave period $T$ as functions of wind speed $U$, water depth $h$ and wind fetch $F$ were calculated from empirical equations for Lake George (Australia) reported by Young and Verhagen [11] and modified by So [2] for Lake Apopka. The wave height was obtained from

$$
\hat{E}=9.3 \times 10^{-3}\left\{\tanh A_{1} \tanh \left[\frac{B_{1}}{\tanh A_{1}}\right]\right\}^{1.97}
$$




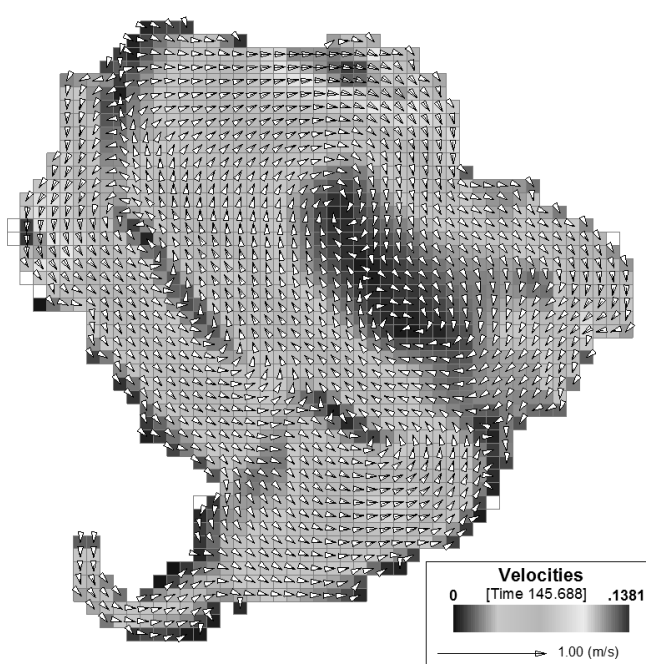

Figure 4: Typical simulated pattern of depth-averaged current vector in Lake Apopka.

where $\hat{E}=g^{2} E / U^{4}, g$ is the gravity acceleration, $E$ is the wave height variance, $A_{1}=0.493 \hat{h}^{0.75}, \hat{h}=g h / U^{2}, B_{1}=3.13 \times 10^{-3} \hat{F}^{0.57}, \hat{F}=g F / U^{2}$. The coefficient of determination $R^{2}$ was found to be 0.69 . As an example calculation, let $U=10 \mathrm{~m} \mathrm{~s}^{-1}, h=2 \mathrm{~m}$ and $F=10 \mathrm{~km}$. From Eq. (8) $\hat{E}=1.32 \times 10^{-4}$ and $E=1.38 \times 10^{-2} \mathrm{~m}^{2}$. Finally the significant wave height $H_{s}=4 \sqrt{E}=0.47 \mathrm{~m}$. Wave period was calculated from

$$
\hat{f}=0.21\left\{\tanh A_{2} \tanh \left[\frac{B_{2}}{\tanh A_{2}}\right]\right\}^{-0.43}
$$

where $\hat{f}=U f / g, f=1 / T, A_{2}=0.331 \hat{h}^{1.01}$ and $B_{2}=5.215 \times 10^{-4} \hat{F}^{0.73}$. The value of $R^{2}$ of 0.29 was low, and the wave period was less dependent on wind than wave height. From eqn (9) we obtain $\hat{f}=0.69, f=0.67 \mathrm{~s}^{-1}$ and $T=1.49 \mathrm{~s}$. Equations (8) and (9) were used in the calculation of $\tau_{b w}$ using eqn (7).

The current speed $u$ at elevations coinciding with the OBS at UF0 could be roughly associated with wind speed. The time-series of $u$ (in the same direction as waves) $0.7 \mathrm{~m}$ above bottom was taken as a characteristic boundary-layer velocity. The simplest relationship $\left(R^{2}=0.30\right)$ was found to be linear:

$$
u=0.006 U
$$

Thus at $U=10 \mathrm{~m} \mathrm{~s}^{-1}$, a relatively high speed at this lake, $u=0.06 \mathrm{~m} \mathrm{~s}^{-1}$, which is a small value reflecting shallow water and limited wind fetch. Equation (10) was used to calculate the current induced bed shear stress $\tau_{b c}$ in eqn (7). 


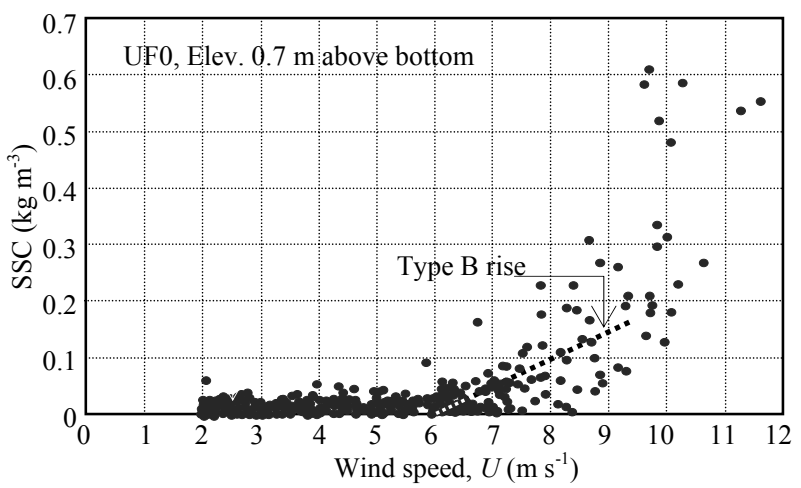

Figure 5: SSC measured by OBS against wind speed 0.7 meters above bottom. Data are from Deployment UF0-05.

\section{Critical wind speed and erosion flux}

The critical wind speed $U_{c}$ (Table 2) has been estimated from the SSC- $U$ plot in Fig. 5 for Deployment UF0-05. There was negligible Type A rise in SSC; the rise began at approximately $6 \mathrm{~m} \mathrm{~s}^{-1}$. Initially the linear rise rate was $0.05 \mathrm{~kg} \mathrm{~s} \mathrm{~m}^{-4}$, which became more rapid above about $9 \mathrm{~m} \mathrm{~s}^{-1}$.

From the Fig. 6 plot of $U_{c}$ against days from the onset of the experiment, we observe the $U_{c}$ was seemingly higher during months of cool water $\left(20-25^{\circ} \mathrm{C}\right)$ in the lake compared with months of warmer water $\left(30-35^{\circ} \mathrm{C}\right)$. Biotic influences at the bottom are believed to change bed stability with water temperature in this lake (Coveney et al. [12]). Furthermore, erodibility of clayey sediment decreases with water temperature because inter-particle bonds forming the bed structure are more stable when the heat content of ambient fluid is low (Lau [13]).

The time-series of hourly erosion flux $\varepsilon$ was constructed directly from the time-series of SSC and the bed shear stress $\tau_{b}$ (calculated from wind speed). Since speeds greater than about $9 \mathrm{~m} \mathrm{~s}^{-1}$ were rare, the data points in Figs. 7(a), (b) is a composite set developed from several deployments. Unfortunately, no clear trend of erosion is evident in the range of bed shear stress greater than about $0.20 \mathrm{~Pa}$. This has led to a limitation in fitting and inter-comparing eqns (1) to (6). Such a limitation can permit the selection of coefficient values depending, for instance, on whether one chooses to emphasizes erosion behavior at low $(<\sim 0.20 \mathrm{~Pa})$ shear stresses or at relatively high shear stresses $(\geq \sim 0.20 \mathrm{~Pa})$. The present purpose is mainly to display the general trends among the equations on a comparative basis, without a focus on a specific range of bed shear stresses.

For plotting the equations, in addition to water density $\rho_{w}=1.00 \times 10^{3} \mathrm{~kg} \mathrm{~m}^{-3}$, the coefficients values are: eqn (1) $\varepsilon_{\max }=1.80 \times 10^{-2} \mathrm{~kg} \mathrm{~m}^{-2} \mathrm{~s}^{-1}, k=4.08 \times 10^{-1} \mathrm{~Pa}$; eqn (2) $\varepsilon_{\max }=1.60 \times 10^{-2} \mathrm{~kg} \mathrm{~m}^{-2} \mathrm{~s}^{-1}, k^{\prime}=2.62 \mathrm{~Pa}^{0.5}$; eqn (3) $M \sigma_{u}^{2}=5.32 \times 10^{-4} \mathrm{~m} \mathrm{~s}^{-1}$, $\tau_{s}=1.40 \times 10^{-1} \mathrm{~Pa}, \alpha=1.76 \times 10^{1}, \beta=0.70, \delta=1$ (a rounded high value); eqn (4) 
$M=4.79 \times 10^{-3}, \tau_{s}=1.20 \times 10^{-1} \mathrm{~Pa}, a_{1}=-1.138, a_{2}=9.999, a_{3}=-5.869, a_{4}=-1.370 ;$ eqn (5) $C_{\varepsilon}=5.6 \times 10^{-2} \mathrm{~kg} \mathrm{~m}^{-3}, \tau_{s}=1.20 \times 10^{-1} \mathrm{~Pa}$; eqn (6) $M^{\prime}=1.00 \times 10^{-1} \mathrm{~kg} \mathrm{~N}^{-1} \mathrm{~s}^{-1}$, $\tau_{s}=1.00 \times 10^{-1} \mathrm{~Pa}$. These values have not been optimized relative to data. The bed shear strength $\tau_{s}$ value has been slightly adjusted depending on the equation; the overall range is $0.10-0.14 \mathrm{~Pa}$, which indicates that the light-weight organic aggregates are generally more prone to resuspension than dense beds of largely abiotic clay flocs (e.g. Partheniades [3]). Equation (5) requires the distributions of the instantaneous bed shear stress, $\tau_{b}$ and the shear strength $\tau_{s}$. Since they are taken from Letter and Mehta [6] for kaolinitic sediment, the application of eqn (5) has only qualitative significance.

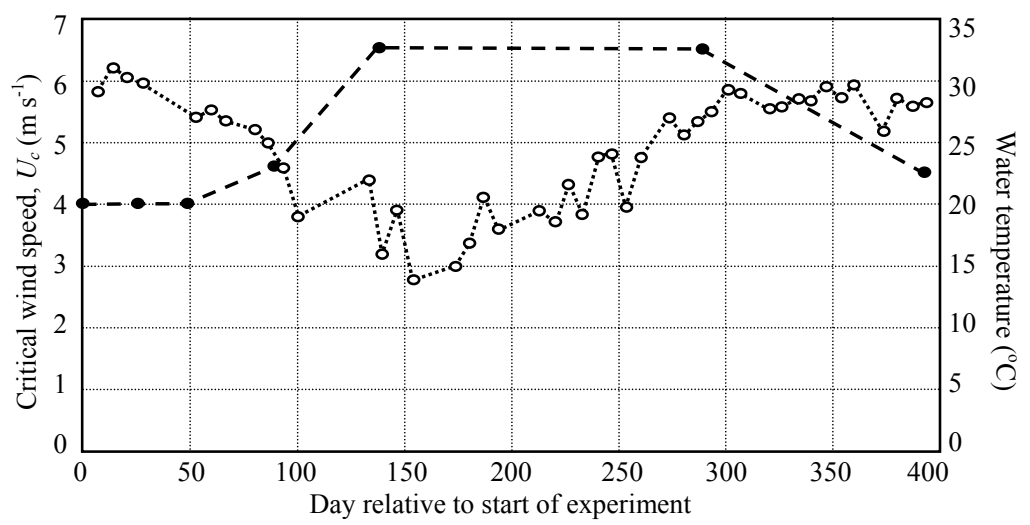

Figure 6: Variation of critical wind speed and (weekly) water temperature during experiment.

In Fig. 7(a) we find that the trends of eqn (1) and eqn (2) are comparable, conditioned as they are by the $\varepsilon_{\max }$ cap. Equation (3) is not constrained in this way and indicates a nearly linear rise in the erosion flux at high shear stresses. In reality a steady rise in $\varepsilon$ can continue only as long as supply of particles from the bed remains unabated and turbulence does not begin to damp due to suspended matter. Since conditions conducive to a steady rise were believed to be present in Lake Apopka due to generally low values of SSC $\left(<0.7 \mathrm{~kg} \mathrm{~m}^{-3}\right)$ even at high wind speeds (e.g. Fig. 5), an inference would be that eqn (3) produces a more realistic trend in the variation of $\varepsilon$ with $\tau_{b}$ than eqn (1) or (2).

Plots of eqns (4)-(6) in Fig. 7(b) show trends that are similar to eqn (3). Although eqn (5) accounts for probabilistic distributions of the bed shear stress and the bed shear strength, its application highlights a constraint because these distributions, especially bed shear strength variability, are rarely available without detailed measurements of bed sediment properties typically obtained in the laboratory setting. 


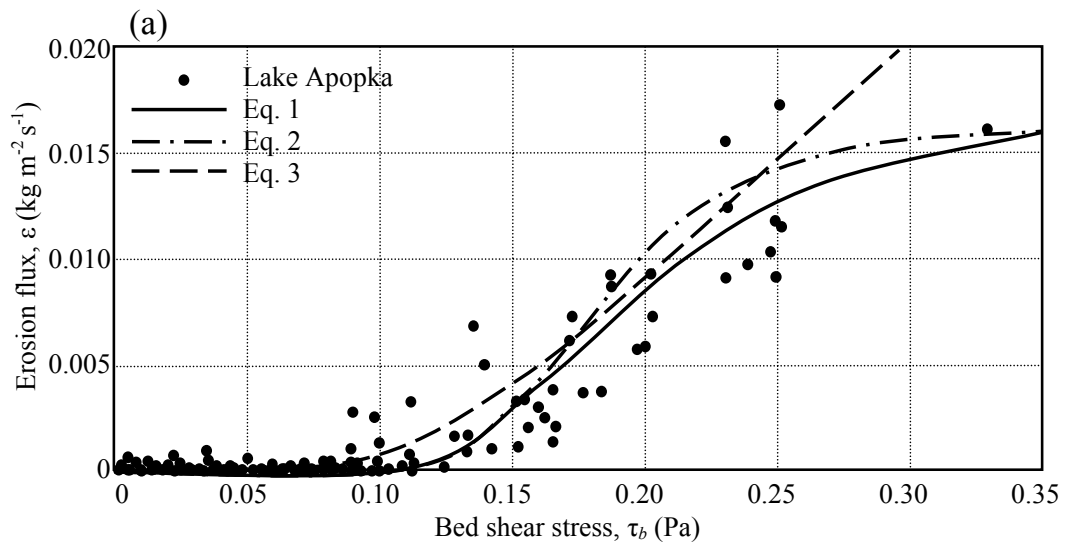

(b)

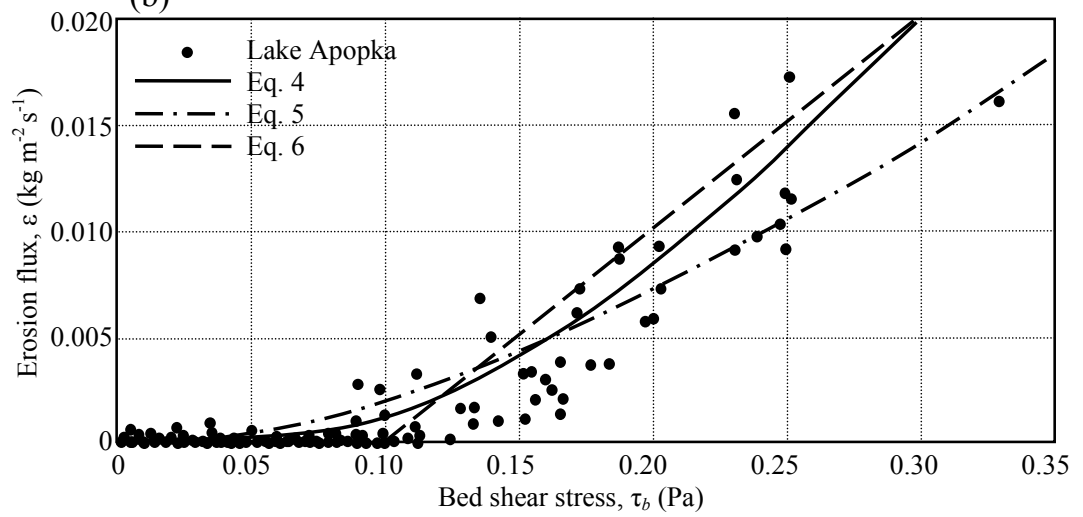

Figure 7: Erosion flux against bed shear stress. Lake data and: (a) Eqs. (1)-(3); (b) Eqs. (4)-(6).

\section{Concluding comments}

The equations include those based on physical principles (eqns (1), (2), (3) and (5)) and those that are empirical (eqns (4) and (6)). The attempt to simulate measurements from Lake Apopka emphasizes that unless the erosion flux shows a consistent trend over the entire range of bed shear stresses, it is difficult to rank the suitability of the equations in the overall sense. At high shear stresses, eqns (1) and (2) have been shown previously to be based on an erroneous interpretation of the criterion for dissociation of the particle from the bed at the instant when the bed shear stress equals or just exceeds the bed shear strength. In any event, more extensive erosion flux field measurements in the upper shear stress range are required to explore this issue. 


\section{Acknowledgements}

The authors acknowledge the St Johns River Water Management District for supporting the field study. We are thankful to Rolland Fulton for his help as the project manager.

\section{References}

[1] State of Florida, Florida quick facts, accessed on November 3, 2012. http://www.stateofflorida.com/Portal/DesktopDefault.aspx?tabid=95

[2] So, S., Fine sediment resuspension in Lake Apopka, FL. MS thesis, University of Florida, Gainesville, 2009.

[3] Partheniades, E., Erosion and deposition of cohesive soils. Journal of Hydraulics Division, ASCE, 91(1), pp. 105-138, 1965.

[4] Christensen, B.A., Discussion of "Erosion and deposition of cohesive soils" by Partheniades, E. Journal of the Hydraulics Division, ASCE, 91(5), pp. 301-308, 1965.

[5] van Prooijen, B.C. and Winterwerp, J.C., A stochastic formulation for erosion of cohesive sediments. Journal of Geophysical Research, 115, C01005, doi:10.1029/2008JC005189, 2010.

[6] Letter, J.V., Jr. and Mehta, A.J., A heuristic examination of cohesive sediment bed exchange in turbulent flows. Coastal Engineering, 58, pp. 779-789, 2011.

[7] Ariathurai, R., A finite element model for sediment transport in estuaries, $\mathrm{PhD}$ Thesis, University of California, Davis, 1974.

[8] Lowe, E.F., Battoe, L.E., Coveney M.F. and Stites, D., Setting water quality goals for restoration of Lake Apopka: inferring past conditions. Journal of Lake and Reservoir Management, 15(2), pp. 103-120, 1999.

[9] Mehta A.J. and Hayter E.J., Effects of some ecohydrological thresholds on the stability of aquatic fine-sediment beds. In: E. Wolanski, D.S. McLusky eds., Treatise on Estuarine and Coastal Science, 9, Academic Press, pp. 425-439, 2011.

[10] Soulsby, R.L., Hamm, L., Klopman, G., Myrhaug, D., Simons, R.R. and Thomas, G.P., Wave-current interaction within and outside the bottom boundary layer. Coastal Engineering, 21(1), pp. 41-69, 1993.

[11] Young, I.R. and Verhagen, L.A., The growth of fetch limited waves in water of finite depth. Part 1. Total energy and peak frequency. Coastal Engineering, 29, pp. 47-78, 1996.

[12] Coveney, M.F., Lowe, E.F., Battoe, L.E., Marzolf, E.R. and Conrow, R., Response of a shallow, eutrophic subtropical lake to reduced nutrient loading. Freshwater Biology, 50, pp. 1718-1730, 2005.

[13] Lau, Y.L., Temperature effect on settling velocity and deposition of cohesive sediments. Journal of Hydraulic Research, 32(1), pp. 41-51, 1994. 